\title{
Absence of Oxidized Phases in Cu Under CO Reduction Conditions
}

Scott, Søren Bertelsen; Hogg, Thomas V.; Landers, Alan Taylor; Maagaard, Thomas; Bertheussen, Erlend; Lin, John C.; Davis, Ryan C.; Beeman, Jeffrey W.; Higgins, Drew; Drisdell, Walter S.

Total number of authors:

15

Published in:

ACS Energy Letters

Link to article, DOI:

10.1021/acsenergylett.9b00172

Publication date:

2019

Document Version

Peer reviewed version

Link back to DTU Orbit

Citation (APA):

Scott, S. B., Hogg, T. V., Landers, A. T., Maagaard, T., Bertheussen, E., Lin, J. C., Davis, R. C., Beeman, J. W., Higgins, D., Drisdell, W. S., Hahn, C., Mehta, A., Seger, B., Jaramillo, T. F., \& Chorkendorff, I. (2019). Absence of Oxidized Phases in Cu Under CO Reduction Conditions. ACS Energy Letters, 4(3), 803-804.

https://doi.org/10.1021/acsenergylett.9b00172

\section{General rights}

Copyright and moral rights for the publications made accessible in the public portal are retained by the authors and/or other copyright owners and it is a condition of accessing publications that users recognise and abide by the legal requirements associated with these rights.

- Users may download and print one copy of any publication from the public portal for the purpose of private study or research.

- You may not further distribute the material or use it for any profit-making activity or commercial gain

- You may freely distribute the URL identifying the publication in the public portal 


\section{Absence of Oxidized Phases in $\mathrm{Cu}$ under $\mathrm{CO}$ Reduction Conditions}

Soren B. Scott, ${ }^{\dagger}$ Thomas V. Hogg, ${ }^{\dagger}$ Alan T. Landers, ${ }^{\ddagger}$, Thomas Maagaard, ${ }^{\dagger}$

Erlend Bertheussen, ${ }^{\dagger}$ John C. Lin, $\stackrel{\ddagger}{\ddagger}$ Ryan C. Davis, J Jeffrey W. Beeman, ${ }^{\perp, \#}$

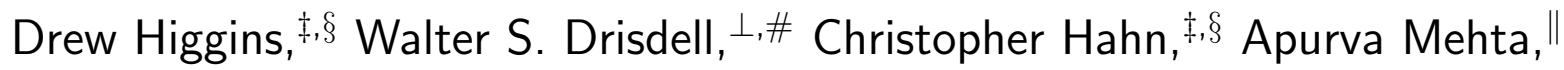
Brian Seger, ${ }^{\dagger}$ Thomas F. Jaramillo, ${ }^{*}, \xi \S$ and Ib Chorkendorf ${ }^{*, \dagger}$

$\dagger$ SurfCat Section for Surface Physics and Catalysis, Department of Physics, Technical University of Denmark, 2800 Kgs Lyngby, Denmark

$\ddagger S U N C A T$ Center for Interface Science and Catalysis, SLAC National Accelerator Laboratory, Menlo Park, CA 94025, USA

IDepartment of Chemistry, Stanford University, Stanford, CA 94305, USA

$\S$ Department of Chemical Engineering, Stanford University, Stanford, CA 94305, USA ||Stanford Synchrotron Radiation Lightsource, SLAC National Accelerator Laboratory, Menlo Park, CA 94025, USA

$\perp$ Joint Center for Artifcial Photosynthesis, Lawrence Berkeley National Laboratory, Berkeley, CA 94720, USA

\#Chemical Sciences Division, Lawrence Berkeley National Laboratory, Berkeley, CA $94720, U S A$

E-mail: jaramillo@stanford.edu; ibchork@fysik.dtu.dk 


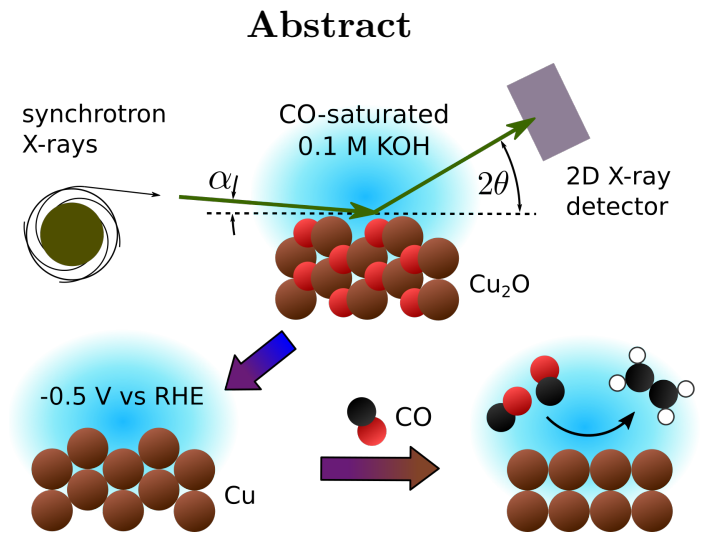

The surface structure and oxide content near the surface of copper electrodes under $\mathrm{CO}$ and $\mathrm{CO}_{2}$ reduction conditions are debated. By live-monitoring $\mathrm{Cu}$ and $\mathrm{Cu}_{2} \mathrm{O}$ Bragg peaks from the surface of a polycrystalline $\mathrm{Cu}$ electrode while scanning from open-circuit potential to $\mathrm{CO}$ reduction potentials, we show that the near-surface region is fully converted to the metallic phase at approximately $+0.3 \mathrm{~V}$ vs RHE. 
Copper can catalyze the electrochemical reduction of $\mathrm{CO}_{2}$ and $\mathrm{CO}$ to multi-carbon fuels with significant activity and Faradaic efficiency, ${ }^{1,2}$ and copper-based gas-diffusion electrodes for reduction of $\mathrm{CO}_{2}$ and $\mathrm{CO}$ to ethylene in alkaline electrolyte are approaching technological viability. ${ }^{3,4}$ However, uncertainty about the atomic structure of the electrode surface and near-surface region under reaction conditions remains a challenge to the development of more active and selective electrodes materials.

Importantly, the presence of oxygen is a matter of debate. Despite the high equilibrium potentials for reduction of bulk oxidized phases of copper $\left(U_{\mathrm{RHE}}^{\circ}>0.4 \mathrm{~V}\right.$, see Table S1), several studies have reported signs that oxygen is present near the surface of copper electrodes under reaction conditions $\left(U_{\mathrm{RHE}}^{\circ}<0 \mathrm{~V}\right),{ }^{5,6}$ and density functional theory (DFT) calculations have indicated that subsurface oxygen may promote $\mathrm{CO}_{2} / \mathrm{CO}$ reduction activity. ${ }^{6,7}$ Other experiments and calculations have indicated that subsurface oxygen is not stable under the cathodic reaction conditions, ${ }^{8-10}$ and recent comparisons have shown that, when properly normalized, the intrinsic $\mathrm{CO}$ and $\mathrm{CO}_{2}$ reduction activity on copper-based electrodes does not depend on the initial oxidation state. ${ }^{2,11}$

In addition to the debate over the presence of oxygen under reaction conditions, insitu scanning tunneling microscopy (STM) studies have indicated that copper surfaces are dynamic under reaction conditions. ${ }^{12,13}$ Additional in-situ methods averaging over a macroscopic sample area can help to confirm and better understand these effects.

We used in-situ grazing incidence X-ray diffraction (GIXRD) with synchrotron radiation to probe the structure of a polycrystalline copper thin film under $\mathrm{CO}$ reduction conditions $0.1 \mathrm{M} \mathrm{KOH}(\mathrm{pH} \approx 13)$, using a three-electrode setup with a flow cell and techniques described in detail elsewhere. ${ }^{14}$ By varying the incident angle $(\alpha)$, GIXRD diffractograms were taken at probe depths of $\approx 2.5 \mathrm{~nm}\left(\alpha=0.15^{\circ}\right)$ and $\approx 20 \mathrm{~nm}\left(\alpha=0.20^{\circ}\right)$. Product quantification is out of the scope of this study, but has been described elsewhere for polycrystalline copper under the same $\mathrm{CO}$ reduction conditions. ${ }^{2}$

Figure 1a shows typical GIXRD diffractograms of a polycrystalline $\mathrm{Cu}$ film in $\mathrm{CO}-$ 
saturated 0.1 M KOH electrolyte, taken at the surface-sensitive incident angle of $\alpha=0.15^{\circ}$ before $(+0.65 \mathrm{~V}$ vs RHE) and after $(-0.4 \mathrm{~V}$ vs RHE) reduction. The first potential is near the measured open-circuit potential (OCP, typically $\approx 0.7 \mathrm{~V}$ vs RHE, see Figure S1), and $\mathrm{CO}$ reduction is significant at the latter potential. ${ }^{2}$ The broad $\mathrm{Cu}_{2} \mathrm{O}(111)$ peak centered at $2 \theta=16.9^{\circ}$ in the pre-reduction diffractogram, attributed to the native oxide formed while the sample is exposed to air and/or at OCP, disappears in the post-reduction diffractogram. In contrast, the metallic $\mathrm{Cu}$ peaks, most noticeably $\mathrm{Cu}(111)$ at $2 \theta=20.1^{\circ}$, grow in the post-reduction diffractogram. The large width of the $\mathrm{Cu}_{2} \mathrm{O}(111)$ peak in the pre-reduction diffractogram indicates that the oxide phase is less crystalline than the metallic phase $(\approx 5$ $\mathrm{nm}$ crystallites compared to $\approx 15 \mathrm{~nm}$, see Figure $\mathrm{S} 2$ ). No peaks for other oxidized $\mathrm{Cu}$ phases such as $\mathrm{CuO}$ or $\mathrm{Cu}(\mathrm{OH})_{2}$ were observed in these experiments. The pre- and post-reduction diffractograms in Ar-saturated electrolyte look similar to those in CO (Figure S3). The high $\mathrm{pH}$ likely plays a role in the formation of long-range order in the $\mathrm{Cu}_{2} \mathrm{O}$ phase at $\mathrm{OCP}$, since $\mathrm{Cu}_{2} \mathrm{O}$ diffraction peaks have not been observed at OCP at lower $\mathrm{pH} .{ }^{14}$

Figure $1 \mathrm{~b}$ shows the live reduction of a fresh sample in Ar-saturated electrolyte. The GIXRD data are shown as a heat map indicating intensity as a function of $2 \theta$ on the vertical axis in the top panel and time on the horizontal axis, with the concurrent electrochemical potential $(U$, swept at $-10 \mathrm{mV} / \mathrm{s})$ and current density $(J)$ in the bottom panel. The $\mathrm{Cu}_{2} \mathrm{O}(111)$ peak disappears and the $\mathrm{Cu}(111)$ peak becomes more intense at approximately $\mathrm{t}=40 \mathrm{~s}$, when the potential is between 0.4 and $0.3 \mathrm{~V}$ vs RHE.

The reduction of electrodes in Ar and $\mathrm{CO}$ are compared in Figure 1c. The normalized integrated intensities for the $\mathrm{Cu}(111)$ and $\mathrm{Cu}_{2} \mathrm{O}(111)$ GIXRD peaks during this experiment are plotted against electrode potential in the upper panel of Figure 1c, with the current density in the lower panel. (The heat map for the sample reduced in CO is shown in Figure S4.) For both samples, the $\mathrm{Cu}_{2} \mathrm{O}(111)$ peak disappears and the $\mathrm{Cu}(111)$ peak grows to maximum intensity between 0.4 and $0.3 \mathrm{~V}$ vs RHE, just cathodic of the standard reduction potential of $\mathrm{Cu}_{2} \mathrm{O}$ (Table S1). Interestingly, whereas the cathodic current wave coincides 

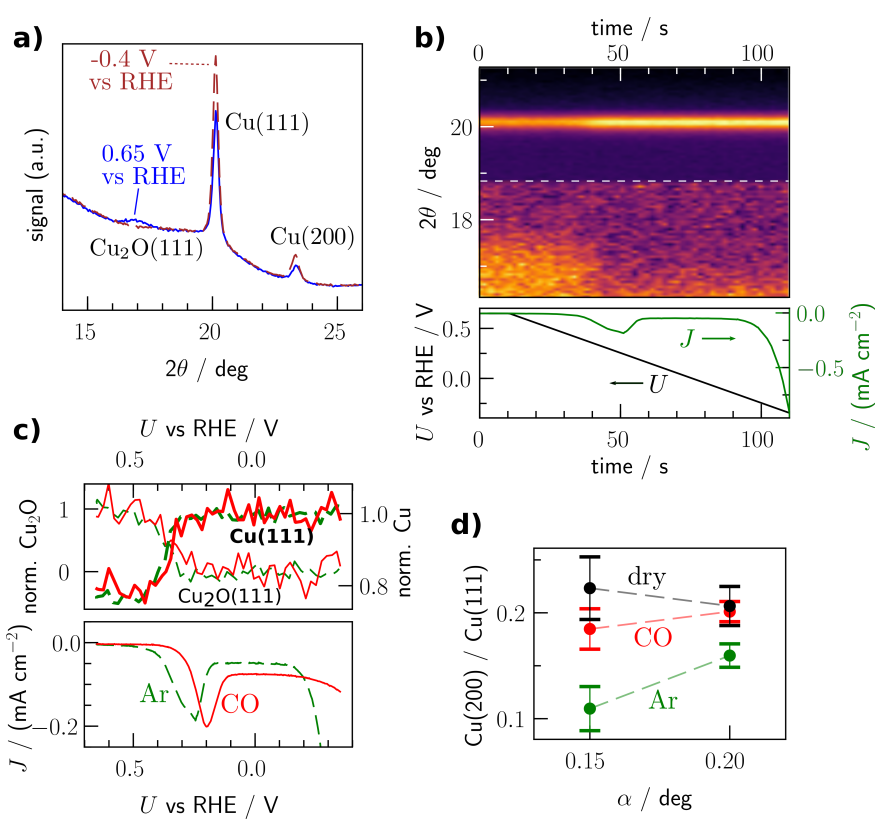

Figure 1: In-situ GIXRD of polycrystalline $\mathrm{Cu}$ electrodes. a) Diffractograms at incident angle $\alpha=0.15^{\circ}$ of a $\mathrm{Cu}$ sample in CO-saturated $0.1 \mathrm{M} \mathrm{KOH}$ before $(U=0.65 \mathrm{~V}$ vs RHE) and after ( $U=-0.4 \mathrm{~V}$ vs RHE) reduction of the surface. b) Live monitoring of diffraction signal $\left(\alpha=0.15^{\circ}\right)$ during reduction of a sample in Ar-saturated electrolyte, with the coinciding potential $(\mathrm{U})$ and current $(\mathrm{J})$ in the bottom panel. c) Integrated $\mathrm{Cu}(111)$ and $\mathrm{Cu}_{2} \mathrm{O}(111)$ Bragg peaks in the top panel and current in the bottom panel during reduction of samples in Ar-saturated (green, dashed lines) or CO-saturated (red) electrolyte. d) The ratio of the integrated $\mathrm{Cu}(200)$ and $\mathrm{Cu}(111)$ peaks for dry samples and reduced samples in $\mathrm{Ar}$ or CO-saturated electrolyte, as a function of incident angle. Points and error bars represent means and standard deviations, respectively.

with the change in XRD peak intensity for the sample reduced in Ar-saturated electrolyte, the current lags the change in peak intensity by 50 to $100 \mathrm{mV}$ for the sample reduced in COsaturated electrolyte. This might indicate an electrochemical reduction mechanism involving a step in which $\mathrm{CO}$ acts as a chemical reducing agent, as $\mathrm{CO}$ is known to reduce copper oxides in thermal catalysis, ${ }^{15}$ but more studies are necessary to confirm the effect.

The increase in the $\mathrm{Cu}(111)$ peak intensity is especially informative: while the scattering signal from a non-crystalline oxidized copper phase might not be discernible from the background scattering signal from the electrolyte, a significant portion of such a phase within the attenuation depth of $2.5 \mathrm{~nm}(\approx 12$ monolayers) would reduce the intensity of the $\mathrm{Cu}(111)$ peak. Since the metal peak abruptly increases in intensity while the potential is $\approx 0.4$ to 
$0.3 \mathrm{~V}$ vs RHE without any subsequent change, significant content of any oxidized phase of $\mathrm{Cu}$ at potentials relevant for $\mathrm{CO}$ reduction seems highly unlikely, as the content of such a phase would have to remain constant from about +0.3 to $-0.5 \mathrm{~V}$ vs RHE. This rules out a significant sub-stoichiometric oxide, crystalline or amorphous, though we cannot rule out minute amounts of oxygen dissolved in the metallic $\mathrm{Cu}$ phase.

Given the low penetration depth, the ratio of peak intensities in GIXRD can be influenced by the surface faceting of a polycrystalline sample, as illustrated in the Supplementary Information (Figure S5). Figure 1d shows the ratio of the integrated intensity of the $\mathrm{Cu}(200)$ Bragg peak to that of the $\mathrm{Cu}(111)$ peak as a function fo incidence angle. The results are grouped into dry samples, reduced samples (-0.4 or $-0.5 \mathrm{~V}$ vs RHE) in Ar-saturated electrolyte, and reduced samples in CO-saturated electrolyte. While this ratio is similar in Ar and $\mathrm{CO}$ prior to reduction (Figure S6), at the small incidence angle $\left(\alpha=0.15^{\circ}\right)$ the $\mathrm{Cu}(200)$ peak increases relative to the $\mathrm{Cu}(111)$ peak in the post-reduction diffractogram for samples in CO saturated electrolyte. The ratios converge at $\alpha=0.20^{\circ}$, confirming that the difference is due to a surface phenomenon. Compared to the dry samples, the $\mathrm{Cu}(200) / \mathrm{Cu}(111)$ ratio is actually lower at $\alpha=0.15^{\circ}$ for both the $\mathrm{Ar}$ and $\mathrm{CO}$ samples. This is consistent with the STM observation of polycrystalline $\mathrm{Cu}$ electrodes which reconstruct first to (111) and then to (100), ${ }^{12}$ and evidences the promotion by CO of the reconstruction to (100)-like surfaces. The CO-promoted transformation to (100)-like surfaces helps explain why polycrystalline $\mathrm{Cu}$ electrodes show high selectivity for CO reduction to ethylene, similar to stepped (100) surfaces. ${ }^{1}$ Small shifts of peak centers $\left(\Delta 2 \theta \approx-0.02^{\circ}\right)$ were also observed during the reduction (Figure S6), possibly reflecting hydrogen-induced expansion. ${ }^{13}$

In this study, we used in-situ grazing-incidence X-ray diffraction (GIXRD) to examine changes in the surface composition and morphology of polycrystalline copper under CO reduction conditions. We showed that the $\mathrm{Cu}_{2} \mathrm{O}(111)$ diffraction peak disappears during the cathodic scan at about $0.3 \mathrm{~V}$ vs $\mathrm{RHE}$ while the $\mathrm{Cu}(111)$ peak simultaneously increases to its maximum intensity, with no further increase at more cathodic potentials, demonstrating 
that the oxide is fully reduced to the metallic phase at potentials relevant to CO reduction. Compared to other studies which also show the reduction of oxidized copper phases prior to the onset of $\mathrm{CO}$ or $\mathrm{CO}_{2}$ reduction by means of in-situ x-ray absorption spectroscopy ${ }^{16}$ and Raman spectroscopy, ${ }^{10}$ our results stand out for the high time resolution and the surfacesensitivity enabled by the grazing incidence configuration. We also provided preliminary GIXRD evidence of preferential surface faceting guided by electrochemical environment, in agreement with STM studies. ${ }^{12}$ Taken together, these results help explain why the intrinsic CO reduction activity of copper-based electrodes is largely invariant regardless of the structure or oxidation state of the precursor. ${ }^{2}$ Surface roughening caused by these faceting changes and transient structures such as undercoordinated sites present during the reconstruction may also contribute to copper's CO reduction activity.

Supporting Information: Experimental details and additional GIXRD data and analysis.

\section{Acknowledgement}

The SurfCat Center for Surface Physics and Catalysis is funded by the Villum Foundation V-SUSTAIN grant 9455 to the Villum Center for the Science of Sustainable Fuels and Chemicals. This material is based, in part, on work performed by the Joint Center for Artificial Photosynthesis, a DOE Energy Innovation Hub, supported through the Office of Science of the U.S. Department of Energy, under Award No. DE-SC0004993. Part of this work was performed at the Stanford Nano Shared Facilities (SNSF) and the Stanford Nanofabrication Facility (SNF), supported by the National Science Foundation under Award ECCS-1542152. X-ray data were collected at Stanford Synchrotron Radiation Lightsource, SLAC National Accelerator Laboratory, which is supported by the U.S. Department of Energy, Office of Science, Office of Basic Energy Sciences under Contract No. DE-AC02-76SF00515. S.B.S. acknowledges the Danish Ministry for Higher Education and Science for an EliteForsk travel 
grant.

\section{References}

(1) Hori, Y. Electrochemical $\mathrm{CO}_{2}$ Reduction on Metal Electrodes. In Modern Aspects of Electrochemistry. 2008, Vol. 42, pp 89-189. DOI: 10.1007/978-0-387-49489-0_3

(2) Erlend Bertheussen, Thomas V. Hogg, Younes Abghoui, Albert K. Engstfeld, Ib Chorkendorff, and Ifan E. L. Stephens. Electroreduction of CO on Polycrystalline Copper at Low Overpotentials. ACS Energy Lett. 2018, 3 (3), 634. DOI: 10.1021/acsenergylett.8b00092

(3) Lihao Han, Wu Zhou, and Chengxiang Xiang. High-Rate Electrochemical Reduction of Carbon Monoxide to Ethylene Using Cu-Nanoparticle-Based Gas Diffusion Electrodes. ACS Energy Lett. 2018, 3 (4), 855-860. DOI: 10.1021/acsenergylett.8b00164

(4) Cao-Thang Dinh et al. $\mathrm{CO}_{2}$ electroreduction to ethylene via hydroxide-mediated copper catalysis at an abrupt interface. Science. 2018, Vol 360 Issue 6390, 783. DOI: 10.1126/science.aas9100

(5) Hemma Mistry et al. Highly selective plasma-activated copper catalysts for carbon dioxide reduction to ethylene. Nat. Commun. 2016, volume 7, article 12123. DOI: $10.1038 /$ ncomms 12123

(6) Andr Eilert et al. Subsurface Oxygen in Oxide-Derived Copper Electrocatalysts for Carbon Dioxide Reduction. J. Phys. Chem. Lett. 2017, 8 (1), 285. DOI: 10.1021/acs.jpclett.6b02273

(7) Marco Favaro, Hai Xiao, Tao Cheng, William A. Goddard III, Junko Yano, and Ethan J. Crumlin. Subsurface oxide plays a critical role in $\mathrm{CO} 2$ activation by $\mathrm{Cu}(111)$ surfaces to 
form chemisorbed $\mathrm{CO}_{2}$, the first step in reduction of $\mathrm{CO}_{2}$. Proc. Natl. Acad. Sci. USA. 2017, 114 (26), 6706. DOI: 10.1073/pnas.1701405114

(8) Yanwei Lum and Joel W. Ager. Stability of Residual Oxides in OxideDerived Copper Catalysts for Electrochemical $\mathrm{CO}_{2}$ Reduction Investigated with ${ }^{18} \mathrm{O}$ Labeling. Angew. Chem. 2018, 57 (2), 551. DOI: 10.1002/anie.201710590

(9) Alejandro J. Garza, Alexis T. Bell, and Martin Head-Gordon. Is Subsurface Oxygen Necessary for the Electrochemical Reduction of $\mathrm{CO}_{2}$ on Copper? J. Phys. Chem. Lett. 2018, 9 (3), 601. DOI: 10.1021/acs.jpclett.7b03180

(10) Lily Mandal et al. Investigating the Role of Copper Oxide in Electrochemical $\mathrm{CO}_{2}$ Reduction in Real Time. ACS Appl. Mater. ES Interfaces. 2018, 10 (10), 8574. DOI: 10.1021/acsami.7b15418

(11) Ezra L. Clark, Joaquin Resasco, Alan Landers, John Lin, Linh-Thao Chung, Amber Walton, Christopher Hahn, Thomas F. Jaramillo, and Alexis T. Bell. Standards and Protocols for Data Acquisition and Reporting for Studies of the Electrochemical Reduction of Carbon Dioxide. ACS Catal. 20188 (7), 6560. DOI: 10.1021/acscatal.8b01340

(12) Youn-Geun Kim, Alnald Javier, Jack H. Baricuatro, Daniel Torelli, Kyle D. Cummins, Chu F. Tsang, John C.Hemminger, Manuel P.Soriaga. Surface reconstruction of pure-Cu single-crystal electrodes under CO-reduction potentials in alkaline solutions: A study by seriatim ECSTM-DEMS. J. of Electroanal. Chem. 2016, 780 (1), 290. DOI: 10.1016/j.jelechem.2016.09.029

(13) Thi Mien Trung Huynh and Peter Broekmann. From In Situ towards In Operando Conditions: Scanning Tunneling Microscopy Study of Hydrogen Intercalation in $\mathrm{Cu}(111)$ during Hydrogen Evolution. ChemElectroChem. 2014, 1 (8), 1271. DOI: 10.1002/celc.201402147 
(14) Maryam Farmand et al. Electrochemical Flow Cell Enabling Operando Probing of Electrocatalyst Surfaces By X-Ray Spectroscopy and Diffraction. Phys. Chem. Chem. Phys. 2019, in press, DOI: 10.1039/C8CP07423B

(15) Eli A. Goldstein and Reginald E. Mitchell. Chemical Kinetics of Copper Oxide Reduction with Carbon Monoxide. Proc. Combust. Inst. 2011, 33 (2), 2803. DOI: 10.1016/j.proci.2010.06.080

(16) Andr Eilert, F. Sloan Roberts, Daniel Friebel, and Anders Nilsson. Formation of Copper Catalysts for $\mathrm{CO} 2$ Reduction with High Ethylene/Methane Product Ratio Investigated with In Situ X-ray Absorption Spectroscopy. J. Phys. Chem. Lett. 2016, 7 (8), 1466. DOI: 10.1021/acs.jpclett.6b00367 